CUPAUAM. 19-1992, 121-143

\title{
NUEVAS CONSIDERACIONES EN TORNO A LA ESCULTURA IBÉRICA
}

Juan Blanquez Perez (*).

UNIVERSIDAD AUTONOMA DE MADRID.

\section{Resumen.}

El presente estudio plantea diferentes cuestiones en torno a la escultura ibérica en piedra, desde una perspectiva metodológicamente obligada: planteando su análisis de un modo parcelado en el espacio y en el tiempo. El significado socio-cultural; el análisis tecnológico; el problema de las cronologías y, por último, el de las destrucciones son las cuestiones principales aquí tratadas y que afectaron a los pueblos ibéricos del s. V a.C. en el litoral alicantino, sureste meseteño y alta Andalucía.

\section{Summary}

This study presents different questions about the stone iberian sculpture from methodological obligations: planting his analysis parceled in the space and in the time. The social and cultural meaning; the technologique analysis; the chronologique problem and, at last, the destructions are the principal questions treated here which affected the iberian poblations of the V century B.C. in the coast of Alicant, south of the Mesetan and High Andalusian.

\section{INTRODUCCION.}

Dentro de los trabajos arqueológicos que venimos realizando en la necrópolis tumular ibérica de Los Villares, en Hoya Gonzalo (Albacete), querríamos destacar la repetida aparición de sucesivos conjuntos escultóricos-arquitectónicos de especial importancia. El interés iconográfico del grupo que aquí presentamos -jinetes y guerreros a caballo- $\mathrm{y}$, sobre todo, el que hayan aparecido colocados in situ, encima de sus tumbas, los convertían en ejemplos excepcionales dentro del panorama de la escultura ibérica. Justificada su importancia hemos creído oportuno adelantar

(*) El presente estudio se engloba dentro de los trabajos que se están desarrollando dentro del Proyecto de Investigación "Estudio tecnológico de la Escultura ibérica en Piedra", subvencionado por la DGICYT (PB90-0175). 
algunas de sus principales características a la espera de posteriores estudios en los que venimos trabajando.

El estudio del mundo funerario ibérico llevado a cabo en los últimos quince años han mejorado notablemente, de tal modo que hoy podemos afirmar que es éste el aspecto mejor conocido de la cultura ibérica (Almagro-Gorbea, 1983; Blánquez Pérez y Antona del Val, 1992). En este contexto religioso-funerario es donde hoy entendemos la arquitectura monumental y su complemento, la escultura. Sin embargo, todavía son importantes las limitaciones de cara a su total comprensión y uno de ellas, posiblemente de las gravosas, sea el cronológico (Blánquez Pérez, 1992a).

Arquitectura monumental y escultura, al servicio de la elites dirigentes, debieron constituir una de las más avasalladoras materializaciones de su elevado estatus social, a la vez que evidenciadoras de su carácter aristocrático-caballeresco (Blánquez Pérez, 1993b). La investigación, así pues, no debe limitarse a una mera valoración tecnológica sino, mas bien, proyectarla de cara al mejor conocimiento de su ideología social, política y religiosa. De ahí la importancia de contar con fechas precisas para los conjuntos escultóricos de Los Villares. Al encuadrar, así, las conclusiones de ellas deduzcamos estaremos caracterizando la sociedad de un momento concreto y, desde esta base, podremos definir mejor su horizonte cultural.

\section{EL YACIMIENTO.}

La necrópolis ibérica de Los Villares se encuentra situada en las estribaciones de los Altos de Chinchilla, próxima a la población actual del mismo nombre y en una zona de tradicional riqueza arqueológica. En efecto, en un área de no mas de $25 \mathrm{kms}$. encontramos numerosos yacimientos citados por la bibliografía que consideramos fundamentales para entender la cultura ibérica. Sin embargo, su conocimiento científico y nivel de publicaciones es muy desigual (Blánquez Pérez, 1984, 185; 1992b, 235).

Esta citada riqueza arqueológica no debemos explicarla como "fruto de la casualidad", ni reducirlo a una simple "zona de paso" (ver fig.1). Exige por nuestra parte un razonamiento científico que conlleve contenido histórico. El registro arqueológico de necrópolis y poblados como Los Villares; El Llano de la Consolación; Hoya de Santa Ana; El Salobral; Pozo Moro; Casa Quemada; Tolmo de Minateda, o La Quéjola manifiestan una intensa y jerárquica ocupación del territorio (Blánquez Pérez, 1993b) favorecida por la existencia de una consolidada red de caminos que aprovechaban al máximo las posibilidades naturales del medio. Muy en particular y para el período que estudiamos habría que destacar la vía Heraclea, auténtico soporte físico sobre el que se configuró la cultura ibérica (Almagro-Gorbea, 1986, 98; Sillières, 1977; Blánquez Pérez, 1990a, 37 y ss.;Idem 1990b).

Las excavaciones llevadas a cabo en Los Villares han documentado un total de 40 tumbas de cubrición tumular, a las que hay que añadir 106 cremaciones mas depositadas en hoyo simple. Todas ellas no constituyen el total original, pero constituyen un conjunto mas que suficiente para elaborar una propuesta histórica del yacimiento.

La necrópolis ocupó una pequeña elevación natural, de no mas de media hectárea, que buzaba de modo natural hacia el suroeste. La generalización de los enterramientos con cubrición tumular a partir de lo que hemos denominado fase II obligo, en aquel momento, a una nivelación artificial. Aquel tipo de cubrición provocó una rápida sobreelevación del terreno, de tal modo que pronto la necrópolis debió destacar físicamente de su entorno. Ello, junto a al volun- 
tario constreñimiento de la zona de enterramientos al área inicial de la necrópolis, favoreció una superposición estratigráfica de casi dos metros que, en la actualidad, se encuentra ligeramente reducida por la erosión provocada por las faenas agrícolas.

De algún manera física el yacimiento debió estar delimitada. Lo podemos deducir gracias a la tajante interrupción de la zona de tumbas inalterada a lo largo de siglo y medio de utilización del cementerio. Ello obligó una progresiva aglomeración de las tumbas y la consiguiente pérdida del ordenamiento original del espacio interno de la necrópolis.

Son tres las fases culturales que hemos podido diferenciar, matizadas por subdivisiones internas. Recientemente publicada la estratigrafía arqueológica (Blánquez Pérez, 1990a, 124; Idem, 1992b, 249) reseñemos sólo sus principales hitos. La Fase I arranca en un momento no preciso de la segunda mitad del siglo VI a.C. pero, con seguridad, ocupó el último cuarto del siglo en función de los elementos de importación (cerámica de fayenza) y objetos de metal (placas de cinturón). Dentro de esta primera fase de la necrópolis se documentaron dos estratos sucesivos susceptibles de interpretación histórica. Los hemos denominado momentos Ia y Ib, siendo el segundo de ellos cuando pensamos que aparecen en el sureste meseteño las tumbas con cubrición tumular.

La Fase II, la más importante y mejor conocida, se desarrolló a lo largo del siglo $\mathrm{V}$ a. de C. Estratigráficamente se diferencian tres niveles dentro de la misma. Son los denominados momentos IIa, IIb y IIc a lo largo de los cuales no se produjeron cambios conceptuales. Mas bien reflejan el paso normal del tiempo que conllevó, entre otras cosas, el recrecimiento de los suelos de uso y una lógica superposición de los enterramientos.

Los dos silicernia aparecidos, un primero denominado Tumba 25 y un segundo perteneciente a la tumba tumular n²0, corresponden a los momentos finales de la Fase II. Los cántaros del grupo IV, V y VI de Saint Valentin fechan, como materiales mas recientes de ambos conjuntos, la finalización de esta fase en torno a la última década del s.V a.C. (Roldán Gómez, 1993a;Eadem 1993b) (ver Lam.1). La práctica totalidad de los elementos escultóricos y arquitectónicos encontrados en el yacimiento pertenecen a esta fase. Nos basamos en la ubicación estratigráfica de los ejemplares sin asociación a enterramientos concretos y en los ajuares de las tumbas para las aparecidas sobre sus tumbas, in situ.

La primera escultura, de las dos que en este trabajo presentamos, apareció sobre una tumba de cubrición tumular hecha en adobes, caso éste único en la necrópolis en cuanto a tipo de material empleado; es la inventariada como Tumba Tumular $\mathrm{n}^{\circ} .18$. Cronológicamente hablando es la mas antigua de las dos y representa un guerrero a caballo. La segunda escultura, realizada casi un siglo mas tarde, muestra una misma iconografía sólo que en esta ocasión el caballero no porta ningún elemento de guerra, es la Tumba Tumular $\mathrm{n}^{\circ} .20$. La escultura apareció caída junto al túmulo con muestras inequívocas de pertenecer a este. Baste, entre otros argumentos, el hueco rectangular sin piedras documentado en la parte superior del túmulo y cuyas medidas coinciden con las del pedestal del caballo.

La Fase III, última del yacimiento, se documentó ya muy alterada por las faenas agrícolas, dada su disposición estratigráfica superficial. Esta nueva fase supuso notables diferencias formales e ideológicas en la necrópolis. Se siguió enterrando en tumbas tumulares pero de peor calidad y menor tamaño, de hecho no se construyeron -o al menos no hemos documentado ninguna cubrición que, en sentido estricto, podamos denominarla "principesca".

A partir de este momento no se guardó ningún cuidado a la hora de realizar nuevos enterramientos. Las tumbas en hoyo simple se dispusieron encima de túmulos anteriores, rompiéndolos. Se generalizó la presencia de cerámica ática, fundamentalmente cílicas, que evi- 
dencian la normalización de este tipo de vajilla tan específica para el consumo del vino. La mayoría de las tumbas de este momento aparecieron destruidas, pero los numerosos fragmentos áticos esparcidos en superficie proporcionan una idea bastante aproximada, tipológica y decorativa, del valor socio-cultural de este tipo de cerámica entre los iberos. De igual modo ha permitido precisar el final de uso de la necrópolis que, al no haber terminado su estudio completo, fechamos provisionalmente en torno al paso del primer al segundo cuarto del siglo IV a. de C.

\section{LOS ENTERRAMIENTOS CON ESCULTURA.}

\section{a).-La Tumba Tumular $n^{\circ} 18$. El complejo.}

La tumba con cubrición tumular que, por sus peculiaridades internas, denominamos complejo apareció estratigráficamente superpuesta al Túmulo 31 (fase IB). Entre ambos enterramientos se documentó un nivel de tierra verdosa que se extiende por gran parte de la necrópolis y que interpretamos como una respuesta consciente destinada a paliar la inclinación natural del terreno hacia el SW. Todo ello de cara a la construcción de tumbas con cubrición tumular que, a partir de este momento, se generalizaron.

La estructura tumular es de planta rectangular, de 3, 50 por 2, $50 \mathrm{~ms}$. con sus lados orientados, como la mayoría de las cubriciones tumulares, en relación con los puntos cardinales (caras cortas a Este y Oeste, respectivamente). El contorno perimetral se alzó en adobes de gran tamaño $(83 \times 9 \times 32 \mathrm{cms}$.) dispuestos en cinco hiladas originales conservadas en la actualidad. La plataforma así delimitada se cerró luego con una capa de adobes de menor tamaño y formas irregulares. Toda esta cubrición supuso un levantamiento en torno al medio metro en relación con su entorno. Encima y con una orientación este-oeste se dispuso la escultura del guerrero a caballo de 1,90 metros de altura.

$\mathrm{Al}$ no haberse conseguido una buena nivelación del terreno en este sector de la necrópolis durante la construcción del túmulo y entre la segunda y tercera hilada de adobes se dispuso, a modo de cuña, una hilada de piedras. De este modo tan sencillo se consiguió la horizontalidad buscada y no perceptible en la construcción al ir toda la cubrición revocada en barro (ver Lam.2).

Coronando el túmulo, tal y como decíamos, mirando hacia el oeste apareció in situ el pedestal de la escultura. De planta rectangular $(30 \times 117 \mathrm{cmts}$.) conservaba unido a él las pezuñas y el final de la cola del animal. El basamento escultórico se mantenía en su sitio original acomodado sobre pellas de greda verde y una serie de pequeñas lajas que calzaban la escultura. La talla de la escultura presentaba un torcimiento de su eje vertical que obligó a calzarlo en el momento de su colocación sobre la tumba. Sobre la plataforma tumular aparecieron la cabeza y tronco del guerrero; así como la cabeza, cuartos traseros y delanteros y fragmentos de las patas del caballo. A mayor distancia, posiblemente arrastrados por el arado, se localizaron uno de los pies del guerrero y numerosos informes (ver Lam.3).

El Túmulo 18 pertenece a los inicios de la Fase II, en su momento lia. Se levantó de modo inmediato a la realización del citado estrato de nivelación del terreno y, estratigráficamente, sobre la tumba tumular $\mathrm{n}^{\circ} .31$ perteneciente al momento Ib de la Fase I. El tiempo transcurrido entre un momento y otro debió ser mínimo. La cronología para el inicio de la Fase II la situamos en el paso del s. VI al V a.C., es por ello el que apuntamos la 
construcción del enterramiento en torno al 490 a.C., con un margen lógico en torno a los 10 años.

Dentro del enterramiento, formando parte del ajuar, destaca la aparición de una lanza de hierro completa, punta y contera a falta sólo del nexo originario de madera. Lo anotamos aquí por varios motivos. Por un lado, su tipología apunta a los tipos mas antiguos ibéricos peninsulares coincidiendo, de manera bastante aproximada, al esculpido en uno de los guerreros de Porcuna (Negueruela, 1990, 71); por otro, por encontrarnos ante una de las evidencias con mayor antigüedad de inclusión material de un arma como parte del ajuar funerario ibérico, dado que su inclusión no se generalizaría hasta entrado el s.IV.

\section{b).- La Tumba Tumular no20.}

La tumba con cubrición tumular $\mathrm{n}^{\circ} 20$ documentó también una planta rectangular, si bien de sección escalonada con dos plataformas superpuestas. En su interior se depositó, además de la urna cineraria, los restos de un banquete ritual interpretado como un silicernium, por emplear un término clásico. En efecto, centrado bajo la cubrición y en un hoyo practicado en el suelo se quemaron in situ una vajilla completa de cerámicas griegas, en su mayoría tipológicamente propias para la bebida de vino. Una vez quemadas se cerró el depósito mediante adobes de 28×36 cms. Rematando la cubrición y directamente sobre ella, al igual que en el caso anteriormente comentado, se dispuso la escultura de un hombre a caballo aunque en esta ocasión su orientación fue Norte-Sur (Blánquez Pérez, 1991b).

Varios son los materiales aparecidos en el silicernium que aportan cronología absoluta al enterramiento y, con ello, a la realización escultórica. Si bien no es éste el lugar mas apropiado donde exponer su valoración cultural (1), si querríamos anotar los diferentes tipos de objetos en él aparecidos dada la concordancia entre ambos.

Diferenciamos, en función del tipo de material, cuatro principales agrupaciones:

a).Metal: bronce (pequeños jarritos); plomo (pequeñas láminas enrrolladas) y oro (placas repujadas pertenecientes a un posible collar).

b).Cerámica: tanto local (a torno y a mano, en su mayoría de base trípode), como importada (una cincuentena de piezas áticas de figuras rojas, Saint Valentin y barniz negro).

c).Marfil: cajas de madera, posiblemente dos, adornadas con placas de marfil y decoración figurada.

d).Pasta Vítrea: piezas para perfume (aryballoi) y de adorno (cuentas de collar).

$\mathrm{Si}$ atendemos a su valor funcional la mayoría de las piezas allí depositadas son para el consumo de vino y, ya en segundo lugar, para perfumes, adorno personal. Todas, en su totalidad, pueden considerarse de claro carácter suntuario.

Por lo que respecta a la cronología del enterramiento, en función de los materiales de importación mas modernos (cantaros de Saint-Valentin, transición de los grupos IV-V al VI de Howard y Johnson) proponemos una cronología del último cuarto del siglo $\mathrm{V}$ a.C. Estratigráficamente, además, la tumba no se encuentra en el nivel último de la Fase II, por todo ello fecha-

(1).- En la actualidad venimos trabajando en torno a un estudio global y completo de los dos silicernia, una vez acabada la restauración de la totalidad de los materiales. Para una visión general del primero de ellos ver Blánquez Pérez, 1990 a, 222. 
mos la escultura en torno al 410 a.C. (ver Lam.4).

\section{LAS ESCULTURAS.}

\section{a).- $\mathrm{El}$ guer rero a caballo (Tumba tumular $\mathrm{n}^{\circ} 18$ ).}

El primero de los conjuntos escultóricos destaca, tanto por su interés tipológico e iconográfico, como por su aportación cronológica que se proyecta a otros hallazgos de diferente yacimientos, como los aparecidos en el Cerrillo Blanco de Porcuna (Negueruela, 1990).

Como bien es sabido, los estudios tipológicos de la escultura y arquitectura ibérica han tenido un punto de inflexión a raíz del descubrimiento y estudio del monumento turriforme de Pozo Moro (Almagro-Gorbea, 1983a; Blánquez Pérez, 1988). Posteriormente, nuevas investigaciones han posibilitado sugerentes propuestas: posibles hornacinas (Castelo Ruano, 1990, 294); fachadas arquitectónicas asociables a espacios de culto, en la Alta Andalucía (Lucas Pellicer, Ruano Ruiz, 1990); esculturas zoomorfas pareadas que, al no ser sillares de esquina, debieron de enmarcar algún tipo de monumento que todavía no alcanzamos a definir, etc.

En la actualidad, analizando estos dos conjuntos de Los Villares que aquí presentamos con sus pedestales dispuestos directamente encima de las cubriciones, sin necesidad de elementos arquitectónicos intermedios, estamos en condiciones de afirmar que nos encontramos ante un nuevo tipo funerario distinto de los tradicionales "pilares-estela" (Almagro-Gorbea, 1983, 7). Parece evidente, pues, que no todas las estelas ibéricas hechas en piedra estarían alzadas sobre pilares (Blánquez Pérez, 1991b). El que esta novedad tipológica coincida con una misma iconografía -un jinete y un guerrero a caballo- apunta a que, muy posiblemente, semejante icono nunca lo tuvo, dejando para la escultura animalística el sobrealzado en pilares.

Mas importantes son, creemos, las novedades iconográficas y cronológicas deducibles de estas dos piezas. El fragmentario estado de conservación del guerrero impide, por el momento, un análisis en profundidad hasta que se acabe su restauración, pronta a finalizar. Sin embargo, consideramos interesante adelantar algunas de sus principales características.

La vestimenta, una túnica (quizás camisa) corta con escote en $\mathrm{V}$, aparece marcadamente ceñida mediante un cinturón de faja ancha y placa de un único garfio, todo ello como es propio de los grandes personajes (ver Lam.5). Se recoge así una tradición en la vestimenta documentada en nuestra península desde época orientalizante (Blázquez, 1983, 411) y que perdurará largamente en la cultura ibérica. Así se testimonia en el cinturón de la Aliseda (Blanco Freijeiro, 1956, 21; Perea, 1991, 154); en uno de los relieves del monumento de Pozo Moro (AlmagroGorbea, 1978, 263); en numerosos exvotos en bronce (Nicolini, 1969, 163;Prados, 1992, 141); o en la placa de cinturón de la favissa de El Amarejo (Broncano Rodríguez, 1989, 84), entre otros muchos ejemplos de muy distinta cronología.

El torso presenta también dos elementos asociados a la vestimenta del guerrero cuyos para-

(2).- La escultura del guerrero a caballo está siendo restaurada en la Escuela Superior de Restaruación y Conservación de Bienes Culturales, bajo la dirección del prof. Luis Priego. A dicha entidad y, muy especialmente, a su profesor, vayan aquí nuestro más sincero agradecimiento. 
lelos mas inmediatos son Los Guerreros de Porcuna. Nos referimos a las denominadas "hombreras en ocho" y su correspondiente correa de sujeción (Negueruela 1990, 119) (ver Lam.6). No es éste el único paralelo formal que encontramos en territorio albacetense. Así, en Casas de Juan Núñez está documentado otro torso de guerrero (Giménez Ortuño 1988) de similares características formales, si bien de talla distinta (ver Lam.7). Ya en la costa, en el Parque de Elche, está documentado otro fragmento de busto ataviado con la citada "hombrera" y cinta de sujeción conservado en su lado izquierdo (Ramos Fernández;Ramos Molina 1992, 42).

Todas éstas piezas corroboran la existencia de un tipo de vestimenta definido asociado a un determinado grupo social, el de la cúpula social ibérica y, por tanto, susceptible de ser interpretado con un valor simbólico y de prestigio. Pero ello no debe extrapolarse a toda la cultura ibéri$\mathrm{ca}$, ha de ser encuadrado en un período preciso y territorio concreto: el s.V a.C. y a lo largo del corredor levantino, sureste meseteño y Alta Andalucía. El que su vestimenta no aparezca completada con armadura de discos, en el caso de Los Villares, permitió al maestro-artesano esculpir la pieza con el suficiente detalle como para no dudar la similitud entre ambos ejemplares. La cabeza, como podremos ver, obedece a otras pautas (ver Lam.8).

A falta de realizar una modulación frontal del rostro y del torso, dada la disposición frontal de la figura humana, pero pendiente dado su estado actual en restauración, nos tenemos que limitar a comentar detalles puntuales (ver Lam.9). Destaca, en primer lugar, el tratamiento del cabello. El guerrero aparece cuidadosamente peinado mediante una técnica de talla precisa. El maestro-artesano marcó una serie de líneas incisas enmarcadoras del modelado principal a modo de boceto. La frente aparece adornada con una fila de pequeños rizos orientados a derecha e izquierda en función de un eje teórico central. La citada simetría también se observa en el resto del peinado marcado mediante líneas incisas y que, recortando las orejas, caen por la espalda en disminución. El peinado acaba por detrás en dos grandes rizos mientras que, sobre el pecho, esculpió dos largos tirabuzones.

Nos encontramos ante un peinado de larga cabellera y estilo marcadamente arcaizante en un momento en que, en el Mediterráneo, ya no se realizaba. Sin embargo, en la Península debió gozar de larga aceptación. En este sentido recordamos el bronce del MAN. ( $\mathrm{n}^{\circ}$ inv.1970/14), un posible mango de puñal (Blázquez, 1983, 427) con una escena de sacrificio en el que el personaje masculino -por cierto con ancho cinturón de placa rectangular- presenta un peinado con bucles (Olmos et alii, 1992, 146). Otra recurrencia fácil de establecer, aunque con interesantes variantes, son algunas cabezas procedentes de la necrópolis de El Llano de la Consolación (Blech;M.;Ruano, E., 1992, 75).

Las características técnicas y estilísticas del conjunto de Porcuna, así como el haber sido concebido como un grupo -aspecto éste inédito dentro de la escultura ibérica- nos inclina a pensar en la presencia directa de un maestro (s) griego, de tradición jonia-oriental (3). No necesariamente tendría (n) que haber venido de la costa asiática sino, mas bien, de Córcega,

3.- La cuestión de la posible influencia jonia a la hora de explicar la gran escultura ibérica en piedra sigue siendo hoy, en el estado actual de nuestras investigaciones, un problema de abierto debate.

A favor de dicha tesis, con matizaciones interesantes, encontramos los trabajos Chapa Brunet (1984, 388; 1986, 238); Almagro-Gorbea (1983c, 458; 1984, 434); Blázquez Martínez y González Navarrete (1985, 68); Blanco Freijeiro (1988, 233); Bendala Galán (1987, 243), o nosotros mismos en trabajos anteriores (Blánquez Pérez, 1991b; 1992a; 1993a).

En línea contraria y a favor de una total autoctonía reseñamos las tesis de Llobregat Conesa (1989a, 363; 1989b, 60; 1993 , 183); Trillmich $(1990,611)$. 
sur de Italia, o Sicilia donde hacia tiempo habrían emigrado, tanto de una manera organizada, como individualmente, numerosos artesanos (Domínguez Monedero, 1991, 250;). Sin embargo, el ejemplar de Los Villares plantea sus propias problemática: no se trata de un grupo; la talla del rostro obedece a otro esquema y tenemos segura su asociación a un enterramiento. Por el contrario, los ejemplares de Porcuna parecen corresponder a un posible heroon.

\section{b).- El jinete a caballo. (Tumba Tumular n⿳202).}

Al oeste de la necrópolis, cercano a su límite occidental, apareció la Tumba Tumular nº20. Caída al este de la plataforma apareció la escultura de un jinete a caballo que conservaba unido su pedestal. Aun a falta de la cabeza y torso de la figura humana no había dudas de que no se trataba de un guerrero. Sus manos sujetaban las riendas del caballo y de su cintura no pendía ningún arma. Nos encontramos, pues, ante una figura varonil de alto estatus social a tenor de su vestimenta (túnica de lino, deducible por la talla estriada), calzado (zapato de suela, lazada y bucle) y su propio carácter de caballero.

Una primera observación técnica de la escultura nos pone de manifiesto la desigual atención, por parte del maestro-artesano, a la hora de trabajar las distintas partes de la pieza. Una materialización simple del caballo, si bien realista sí tenemos en cuenta que éste nunca debió ser visto a la altura del espectador sino desde una posición de altura, dominante (ver Lam.10). Pero, de forma paralela, talló la dignidad del personaje mediante su vestido y calzado, la parte mejor trabajada del conjunto.

Bajo nuestro punto de vista los partes trabajadas con mayor esmero serían aquellas que mejor proyectarían el mensaje ideológico del grupo dirigente al que pertenecería el difunto y, en definitiva, los de mas fácil lectura por parte del potencial espectador, esto es, el resto de la sociedad (ver Lam.11). Legible, pues, por la población ibérica la elite habría encontrado en la escultura en piedra uno nuevo vehículo propagandístico, a la vez que justificador, de la rígida estructuración social propia de aquel momento: una sociedad aristocrática-caballeresca que habría de perdurar a lo largo de todo el siglo V a.C. (Blánquez Pérez, 1993b), para luego cambiar significativamente.

Nos encontramos ante una obra de escuela, entendido en un sentido laxo de la palabra. Actualmente, la parte conservada mide $1 \times 1,20 \mathrm{~ms}$., pero su altura debió ser mayor dado que no se ha conservado ni el tronco, ni la cabeza del jinete que supondría, calculamos aproximadamente, unos $0,60 \mathrm{mts}$. mas. La rotura que hoy vemos es antigua, posiblemente provocada por la caída intencionada de la pieza fuera de la plataforma y que conllevó el arrancarla, desplazándola, de su enclave original. En este sentido creemos esclarecedor el que, una vez delimitada durante la excavación la plataforma tumular de sillarejo, se observó un área rectangular de 0 , 20x1, 00x0, $30 \mathrm{~ms}$. sin piedras que coincide con las medidas del pedestal (ver Lams.12 y 13).

La parte conservada no presente golpes, o fracturas, intencionadas y en el entorno no se ha encontrado ningún resto de la parte superior del jinete. La destrucción de los estratos de la fase III, a causa de las labores agrícolas, provocó a nuestra escultura una indebida superficialidad estratigráfica que afectó a su conservación. De este modo, la cara superior (derecha) nos ha llegado muy alterada por las rejas del arado y, posiblemente, también explique la definitiva pérdida de la parte superior de la estatua. Pero, en ningún momento, llegó a arrastrarla de su lugar de caída, encijada como quedó entre su tumba y los escalones de otra principesca contigua (Tumba Tumular $\left.\mathrm{n}^{\circ} 13\right)$. 


\section{CONCLUSIONES.}

Dado lo limitado de estas páginas no hemos pretendido agotar aquí la interpretación cultural posibilitada por las esculturas de Los Villares. Investigaciones que actualmente desarrollamos darán cumplida cuenta de ello. Pero dado que, tras el hallazgo de Pozo Moro, disponemos de nuevas esculturas fechables por criterios arqueológicos y arropadas por contextos precisos, nos encontramos ante la ocasión de proponer una primera valoración de conjunto.

La lectura que aquí exponemos no quiere ser definitiva. Nuestra pretensión es colaborar en pro de una mejor definición del papel jugado por la gran escultura en la sociedad ibérica; encuadrar, con criterios arqueológicos el problema de su cronología y, por último, apuntar la necesidad de una mayor precisión en torno al problema de las "destrucciones ibéricas".

\section{La escultura.}

Hoy día la investigación actual ha dejado de plantear la escultura ibérica como una mera producción provincial secundaria de la griega. Todo lo contrario, la entendemos como una de las mas importantes manifestaciones de su propia identidad. Esta lectura "interna", como en ocasiones se ha defendido (Chapa brunet, 1986, 54; Llobregat Conesa, 1989, 56) no contradice que en lo tecnológico tengamos que alzar la vista al ámbito Mediterráneo.

Un repaso de la documentación disponible, previa al horizonte ibérico, evidencian una falta absoluta de escultura en bulto redondo y gran tamaño. Excepción de lo dicho serían el león de la necrópolis de Almuñecar (Almagro-Gorbea, 1983d, 103) y, si aceptamos una cronología antigua, el monumento turriforme de Pozo Moro (Blázquez Martínez, 1983, 81; Bendala Galán, Blánquez Pérez, 1985, 17; Bendala Galán, 1987, 239) pocos ejemplos mas podríamos citar.

La aparición del conjunto escultórico del Cerrillo Blanco de Porcuna es repentina y, sin embargo, técnicamente hablando evidencia ser una obra lograda. Es por ello que no nos parece oportuno justificar su existencia como resultado evolutivo de una tradición anterior. El conjunto de los guerreros, pensamos, no podría explicarse técnicamente a partir de una evolución interna. Con el hallazgo jiennense nos encontramos ante un producto impropio de un período de balbuceos, al margen ahora de su interpretación iconográfica que, por supuesto, ha de hacerse desde la órbita mental y social del ibero. Aceptar lo primero no presupone, entonces, una devaluación de la categoría cultural ibérica, mas bien lo contrario.

La interpretación cultural de los contextos arqueológicos evidencian que el ibero realizó con frecuencia una reinterpretación de los elementos mediterráneos que incorporaba a su acerbo cultural. Ello fue facilitado, sin duda, por su continua llegada, primero de mano fenicia, griega y púnica por una motivación fundamentalmente económica. Nuestros esfuerzos deben encauzarse, pues, en evaluar el grado y alcance de dichas transformaciones; analizándolas siempre cada ejemplo de modo individualizado y, para el caso de la escultura ibérica en piedra, con la circunstancia añadida de encontramos ante una de las mas importantes materializaciones de su ideología social, política y religiosa.

Es con estas premisas como mejor se entiende la evidencia arqueológica de que en el mundo ibérico "en ningún caso hay esculturas propiamente griegas" (Blech, 1987, XXV). La sociedad ibérica adoptó, de modo selectivo, ideas, mitos e iconografías mediterráneas (Almagro-Gorbea, 
Olmos Romera, 1981) que aplicó a sus propias necesidades. Y es en ello donde encontramos uno de los rasgos mas característicos de su personalidad.

Dentro del proceso interno que supuso la consolidación de cultura ibérica habría pues que admitir la puntual importación de una tecnología y, muy posiblemente, de especialistas. Todo ello facilitado gracias a la presencia griega en la península, si bien no con un carácter propiamente colonial (Blánquez Pérez, 1990c, 19; Idem, 1992a). Con ello, algunos pueblos ibéricos, los de mayor antigüedad cronológica en su proceso formativo, encontraron en la escultura en piedra una de sus más características manifestaciones materiales reflejo, a su vez, de su estructura social de corte aristocrático y caballeresco.

Las similitudes iconográficas del guerrero de Los Villares (monumento A) con los ejemplares de Porcuna y dado lo excepcional de ésta última hace lícito suponer que nos encontramos ante realizaciones acometidas con escaso margen cronológico. Proponemos, basándonos en ello, una fecha para los Guerreros de Porcuna semejante a la de Los Villares, es decir, en torno al 490 a. de C. Por desgracia, la posibilidad de que se trate de los mismos artesanos es algo que, por el momento, no podemos determinar.

Los restantes paralelos citados con anterioridad, los torsos de Casas de Juan Núñez y La Alcudia; o la cabeza de caballo de Casa Quemada (ver Lams.14 y 15) evidencian la rápida difusión de esta iconografía favorecida, a su vez, por la existencia de una red de caminos naturales vertebrados en función de la vía Heraclea. Ello, a su vez, nos obliga a llamar la atención en la no existencia de una retardatio, fruto mas de ideas peyorativas que de testimonios arqueológicos dado que éstos evidencian lo contrario (Blánquez Pérez, 1992a).

El Monumento B realizado casi un siglo mas tarde presenta, no obstante, rasgos iconográficos arcaizantes; de haber aparecido descontextualizado bien se podría haber fechado con mayor antigüedad. Ello manifiesta lo que, para nosotros, es una de las características de la escultura ibérica: la perduración de elementos iconográficos arcaizantes (recuérdese el peinado del guerrero anterior) en coexistencia, sin ningún problema, con la introducción de nuevas formas. De lo que se deduce una segunda consecuencia: el que mitos e iconografía no supusieron esquemas rígidos, o cerrados.

En esta misma línea, pero en un ejemplo mas tardío, tendríamos el cipo de Jumilla (Muñoz Amilibia, 1987; Blázquez Martínez, 1988). Sobre un tema "helenizado", como es la procesión de jinetes, se mantuvieron detalles conceptuales mucho más antiguos: caballos pisando diferentes animales o, incluso, una cabeza humana (Olmos, 1986, 22). Pendiente todavía de una completa lectura iconográfica constituye, no obstante, una muestra mas de la marcada personalidad ibérica (Blázquez Martínez, 1988, 506).

Si revisamos los catálogos escultóricos publicados hasta la fecha podríamos.deducir que la escultura ibérica no tuvo una evolución lineal y única fruto de un exclusivo desarrollo interno. De manera intermitente encontramos materializados en piedra modelos iconográficos que no podemos hacerlos derivar de otros anteriores. Suponen, mas bien, el arranque de esquemas o líneas que, según los casos, tuvieron mayor o menor aceptación repitiéndose muchas veces técnicamente a peor y, lo que es mas importante, sin evidenciar una evolución interna.

No habría, por ejemplo, que buscar antecedentes formales a realizaciones como el conjunto de Porcuna. Si, por el contrario, posibles perduraciones que nos estarían indicando su impacto y utilización simbólica-ideológica en la sociedad ibérica. Los modelos iconográficos llegarían a la Península configurados, sin que ello fuera óbice para posibles y lógicas reinterpretaciones adap- 
tándose a las específicas necesidades de la elite ibérica.

En el último cuarto del s.VI a.C., según la cronología tradicional basada en criterios estilísticos (Chapa Brunet, 1986, 238; Bendala Galán, 1987, 240) y, desde principios del s. V, a tenor de la documentación arqueológica disponible (Blánquez Pérez, 1991c;Idem, 1992a), las elites dirigentes ibéricas del sureste meseteño y Alta Andalucía empezaron a demandar una producción escultórica. Facilitado por el progresivo enriquecimiento iniciado en época tartésica, pero acelerado ahora gracias al comercio griego, la elite social encontró en la materialidad de la gran escultura un modo mas de evidenciar su elevado estatus $y$, ya puntualmente, a través de su iconográfica, justificar ideológicamente sus privilegios.

La existencia desde antiguo en la península de talleres escultóricos (Ruano Ruiz, 191987, 151), si bien no identificados arqueológicamente en el estado actual de la investigación; o la pronta generalización de éste producto, aunque reducido su uso a la elite dirigente constituyen, bajo nuestro punto de vista, uno de los mejores reflejos del triunfo político de una sociedad fuertemente jerarquizada, de estructura piramidal, donde el criterio ordenador debió ser el rango aristocrático-caballeresco en un fenómeno paralelo al de otras culturas mediterráneas.

Las tumbas de estructura tumular; el rápido desarrollo de la escultura y, dentro de la misma, la proliferación del tema iconográfico del guerrero (o jinete) a caballo son pruebas arqueológicas de lo aquí propuesto. Paralelamente, si aceptamos que el comercio a gran escala incide de manera positiva sobre los procesos de urbanismo y jerarquización social (Santos Velasco, 1989, 136) en el territorio nuestro de estudio los ejemplos son paradigmáticos.

Ya para terminar querríamos eludir aquí, aunque sea de pasada, un aspecto ligado a la gran escultura en piedra y que creemos necesitado de un mayor y riguroso estudio. Nos referimos al problema de la, tan citadas, destrucciones ibéricas. Repetidamente citado en estudios recientes (Blanco Freijeiro, 1986-87;Ruano Ruiz, 1987, 86;García-Gelabert, Blázquez Martínez, 1993;), quizá los trabajos se han caracterizado por un criterio mas recopilador que crítico.

Apuntamos, pues, la conveniencia de un planteamiento crítico de la documentación existente como cuestión previa a su interpretación histórica. Es imprescindible una relectura de todo lo publicado sobre el tema, ya que no toda tiene una misma validez. Diferenciar entre roturas intencionadas (las menos) y roturas casuales ya en época antigua, o actual a causa de las faenas agrícolas (las más) es básico de cara a un Catálogo de Destrucciones, todavía sin hacer (4). De igual modo habría que acotar el abanico cronológico abarcado por este fenómeno, hoy por hoy artificialmente amplio a causa del empleo de propuestas cronológicas que son revisables.

De este modo es posible se confirmen las pautas que se observan mediante el análisis tecnológico de la escultura ibérica. Por un lado, la reducción cronológica del período abarcado por las destrucciones; por otro, el que el ámbito espacial afectado sea mas reducido y que afectara, sólo, a determinadas iconografías. Algo hasta el momento no cuestionado en la bibliográfica al uso.

(4).- En este sentido estamos trabajando en el proyecto de la DGICYT (PB90-0175) al elaborar un catálogo de las mismas tras un examen minucioso de las piezas. 


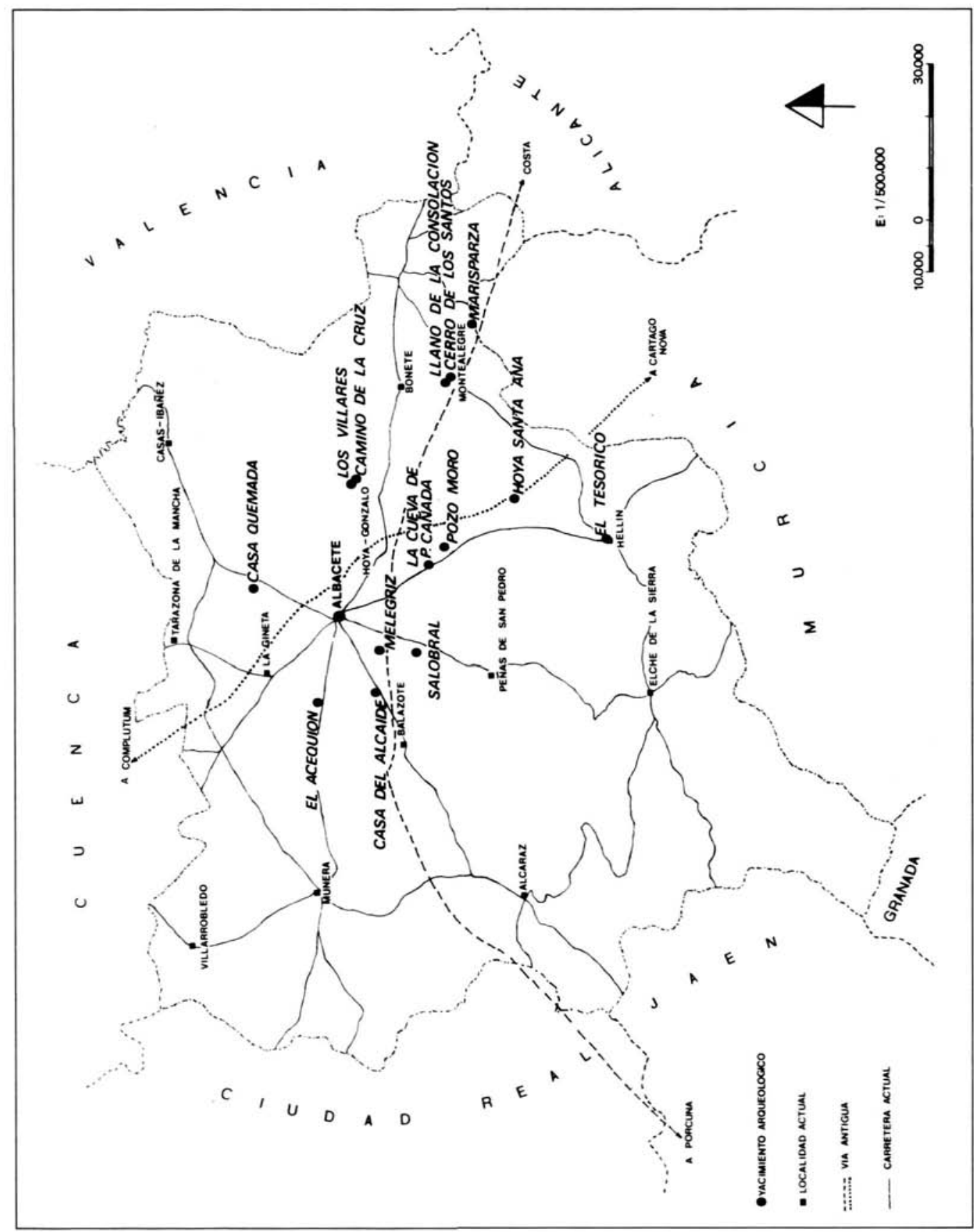

FIG.1- Mapa de la actual provincia de Albacete (sureste de la Meseta), con los principales yacimientos ibéricos. 


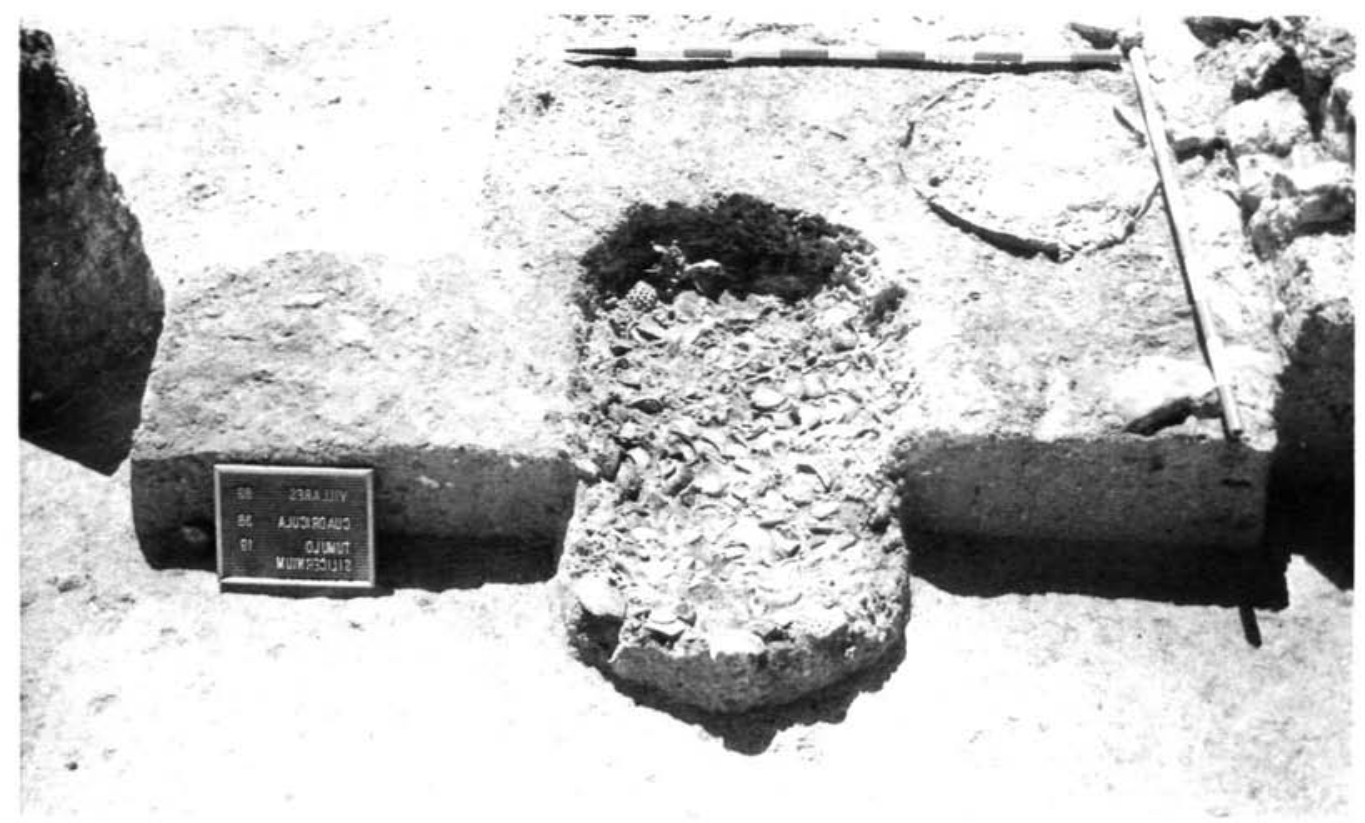

LAM.1- Vista general del silicernium de la Tumba Tumular no.20.

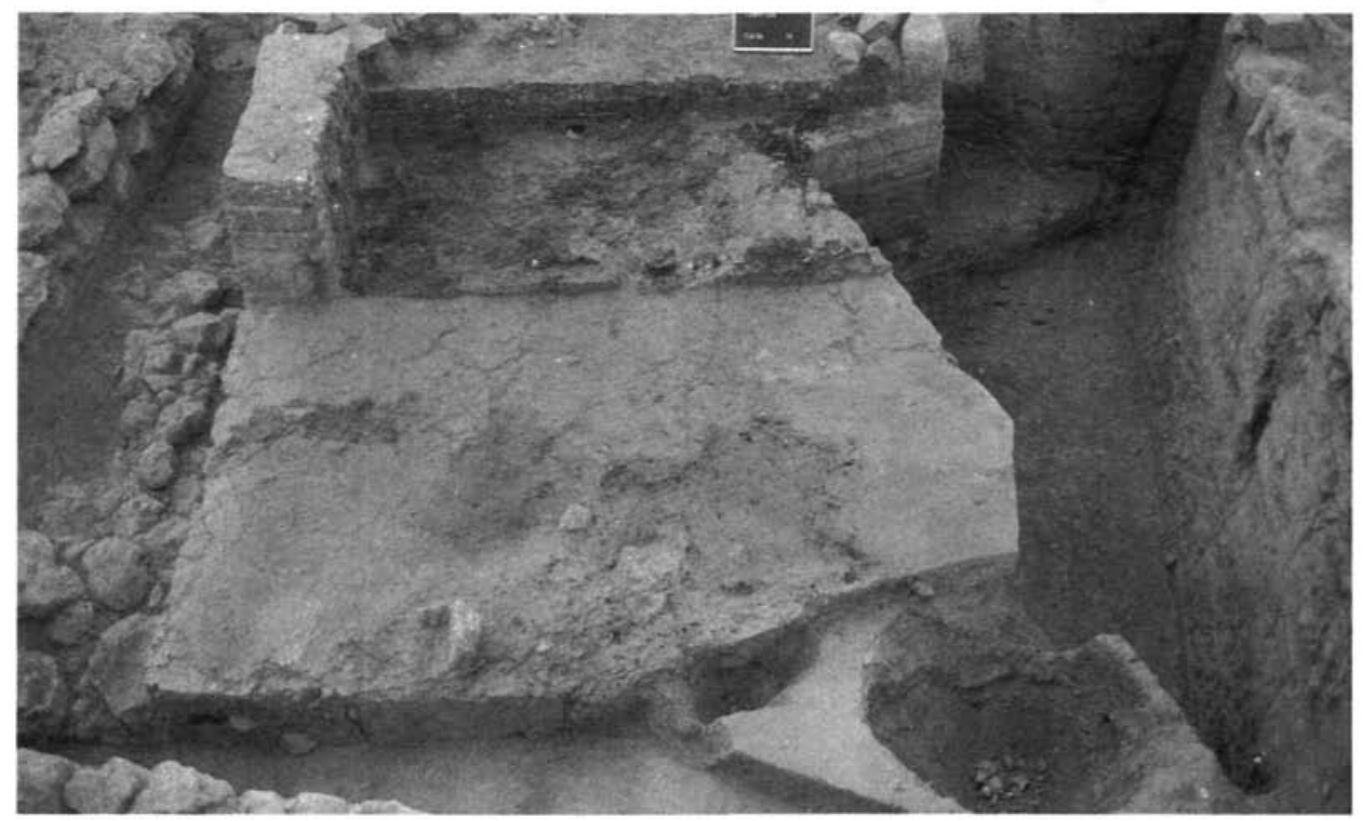

LAM.2- Nivelación con viedras de la Tumba Tumular nº.18. 


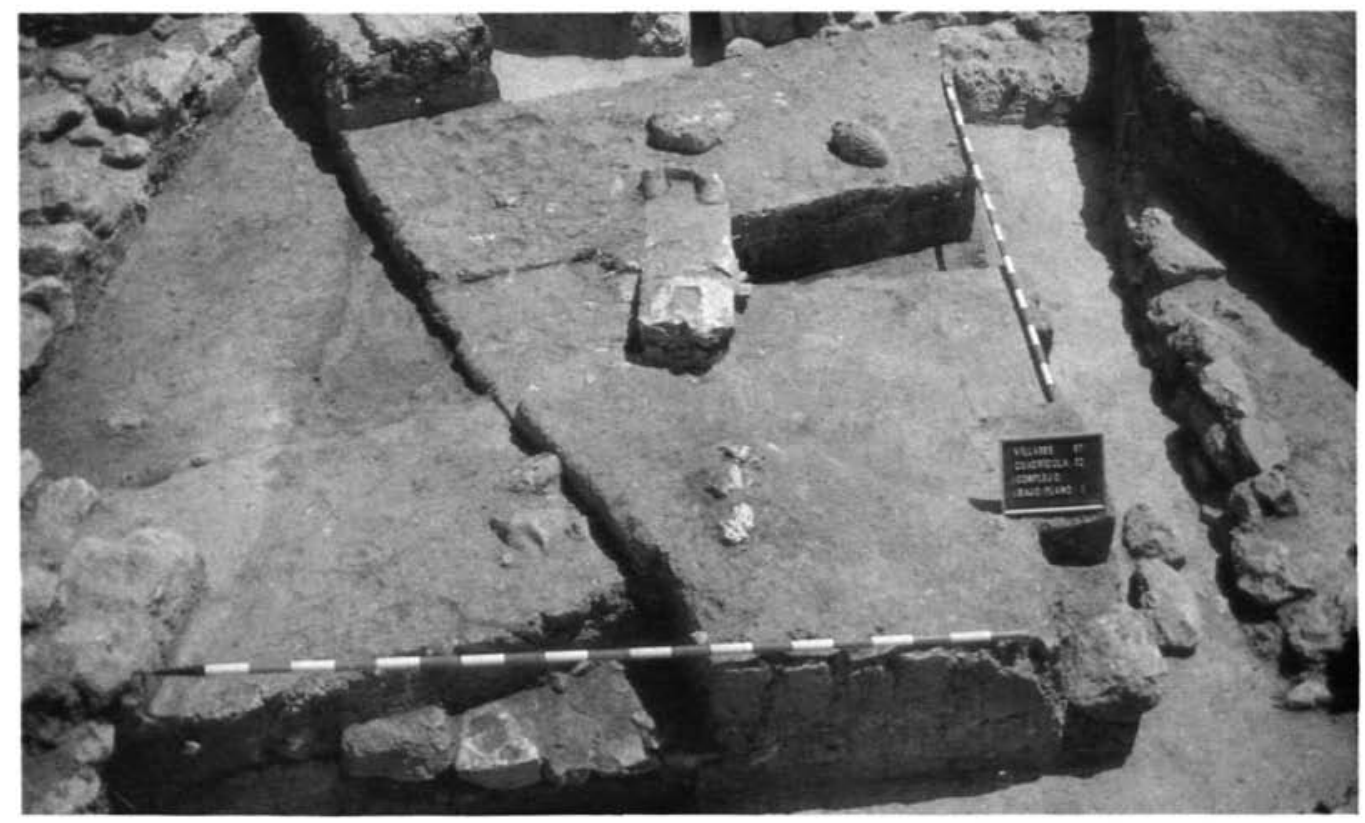

LAM.3- Vista general de la Tumba Tumular no.18.

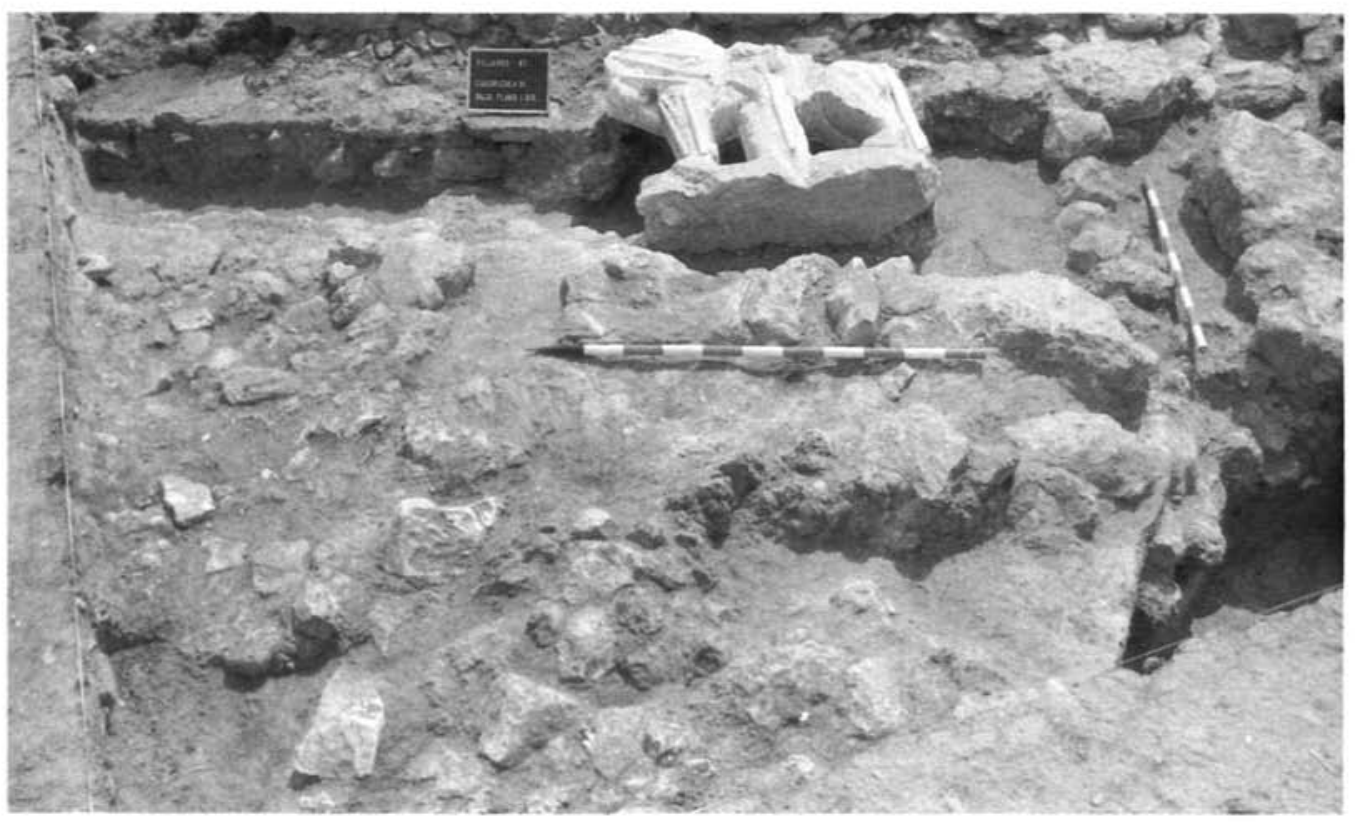

LAM.4- Vista general de la Tumba Tumular $\mathrm{n}^{\circ} .20$. 


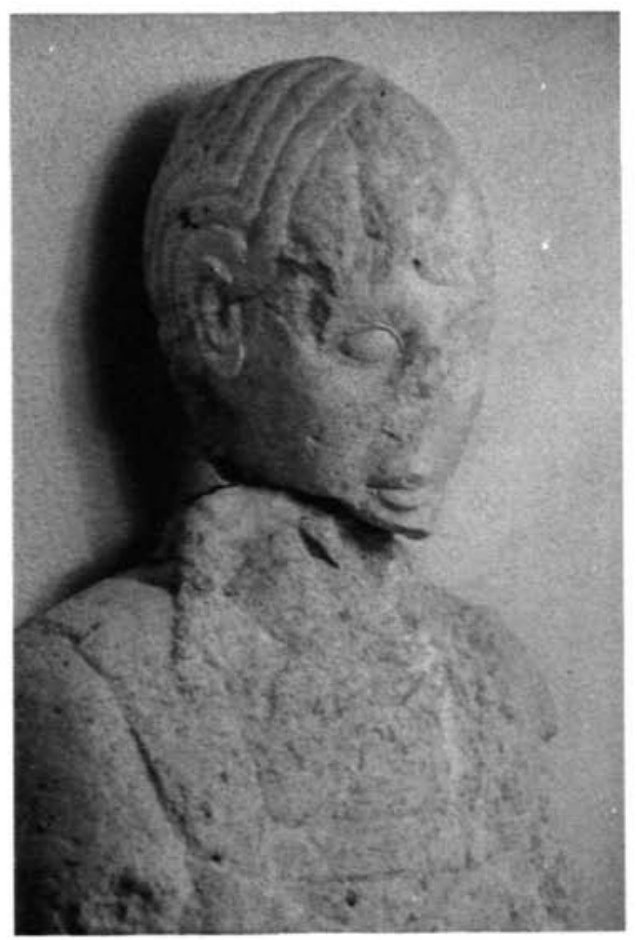

LAM.5-

Detalle del torso del guerrero de la tumba $\mathrm{n}^{\circ} .18$.

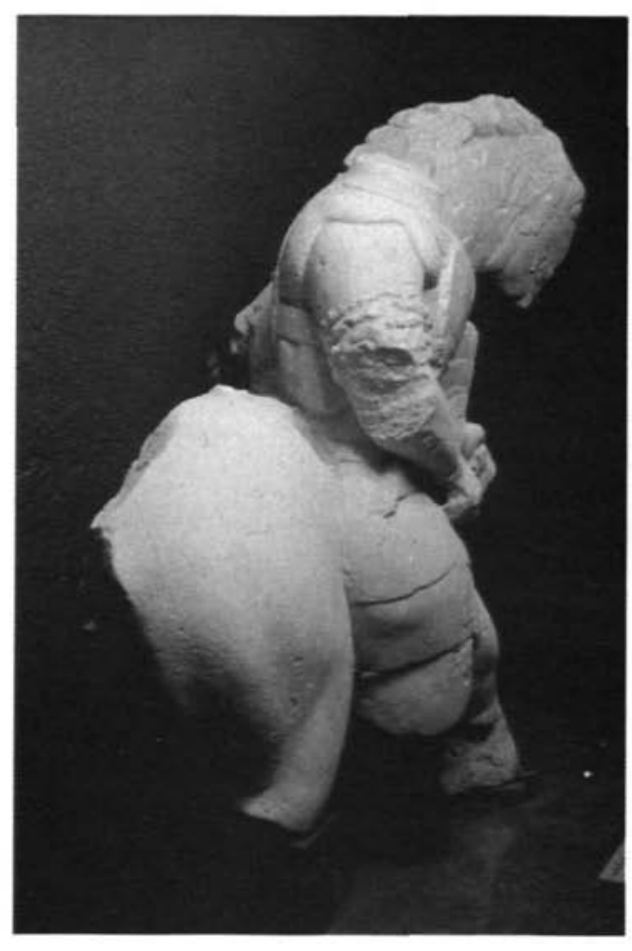

Torso de guerrero del Cerrillo Blanco de Porcuna

(Jaén). 


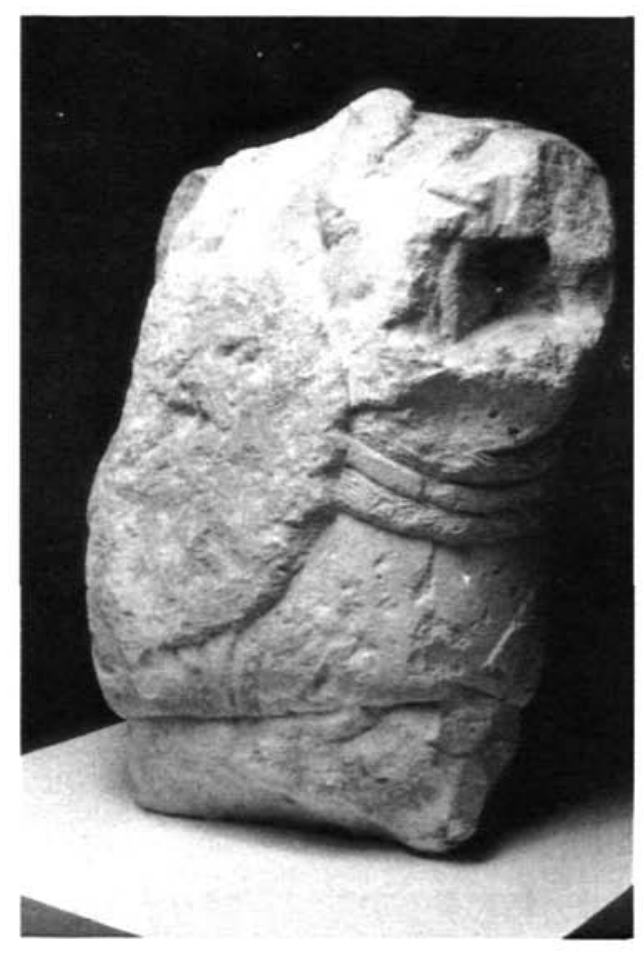

LAM.7-

Torso de guerrero de Casas de Juan Nuñez (Albacete).

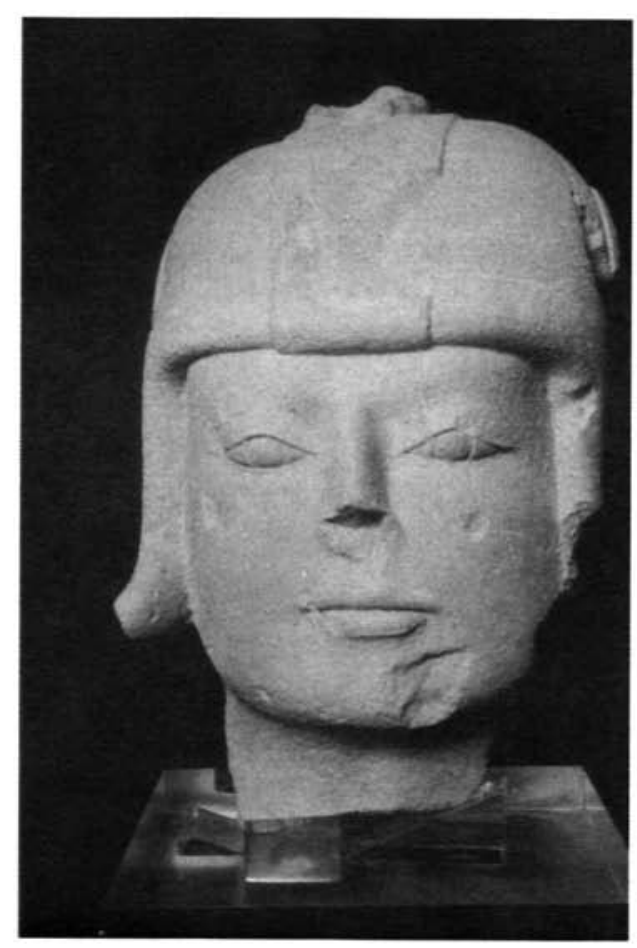




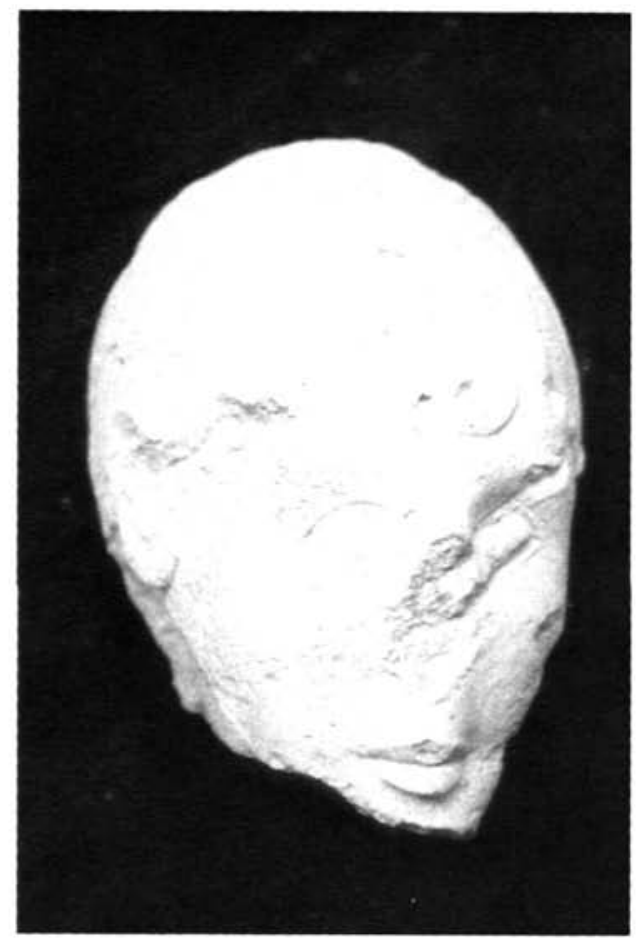

LAM.9-

Cabeza de guerrero de Los Villares

(Hoya Gonzalo, Albacete).

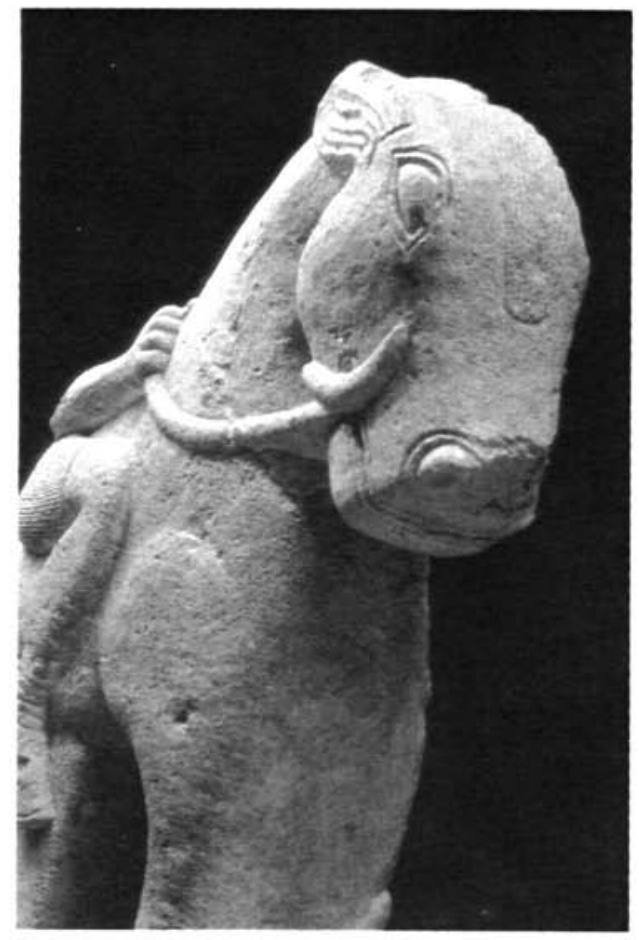
de caballo de la tumba no.20 de Los Villares. 


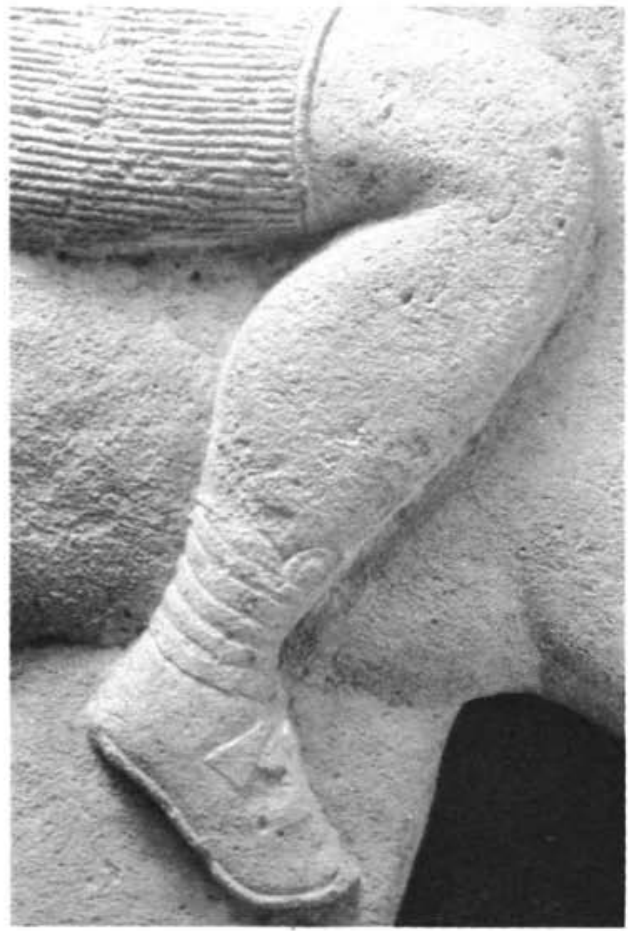

LAM.11-

Detalles iconográficos tratados con csmero en la talla. Escultura de l.1 numb $n^{\circ} .20$ de

Los Villares (Hoya Gonzalo, Albacete).

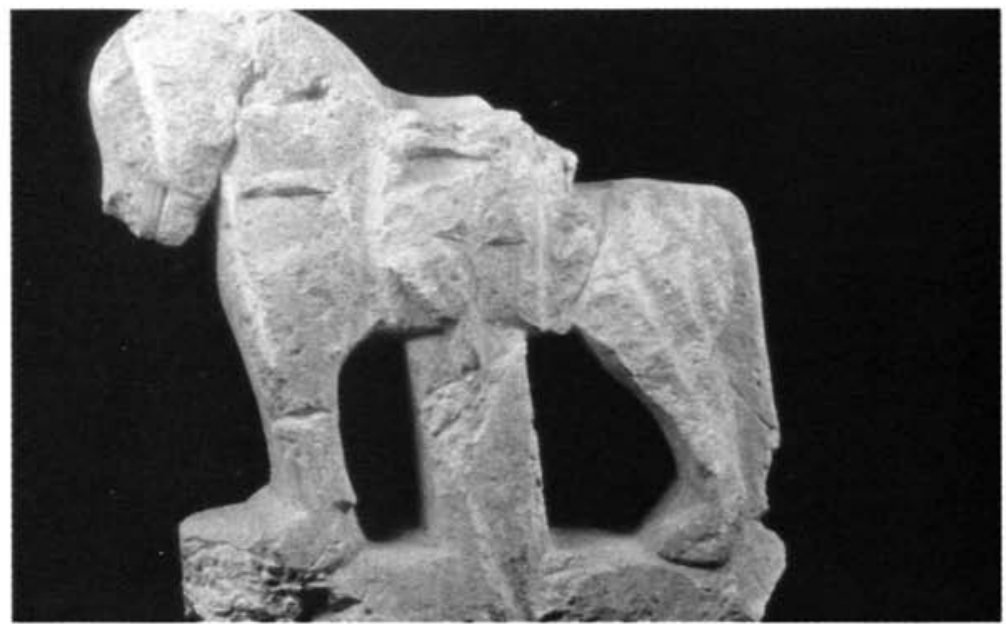

LAM.12- Vista general de la escultura de la tumba $\mathrm{n}^{\circ} .20$ Jinete a caballo, lado alterado por las rejas del arado. 


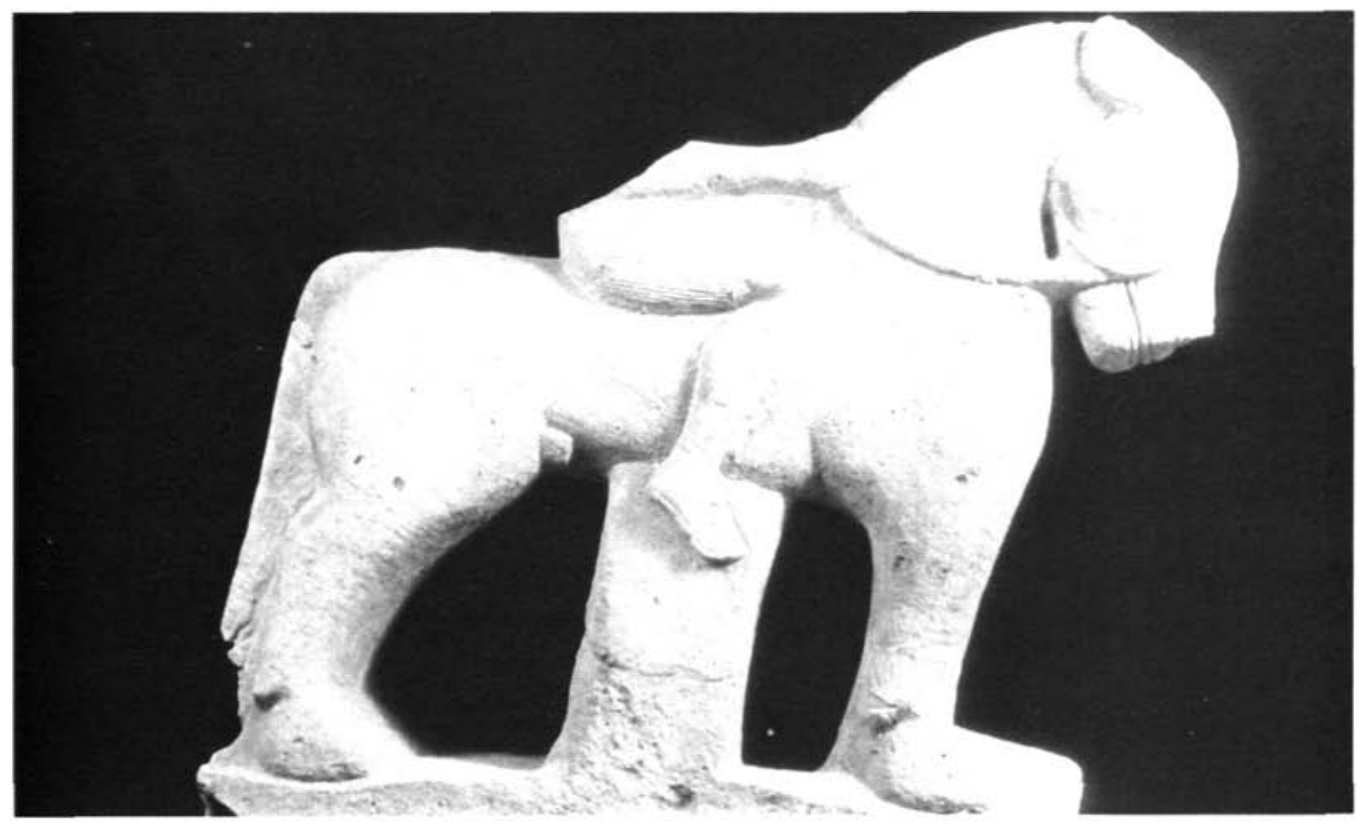

LAM.13- Idem, lado protegido por la propia caida de la escultura.

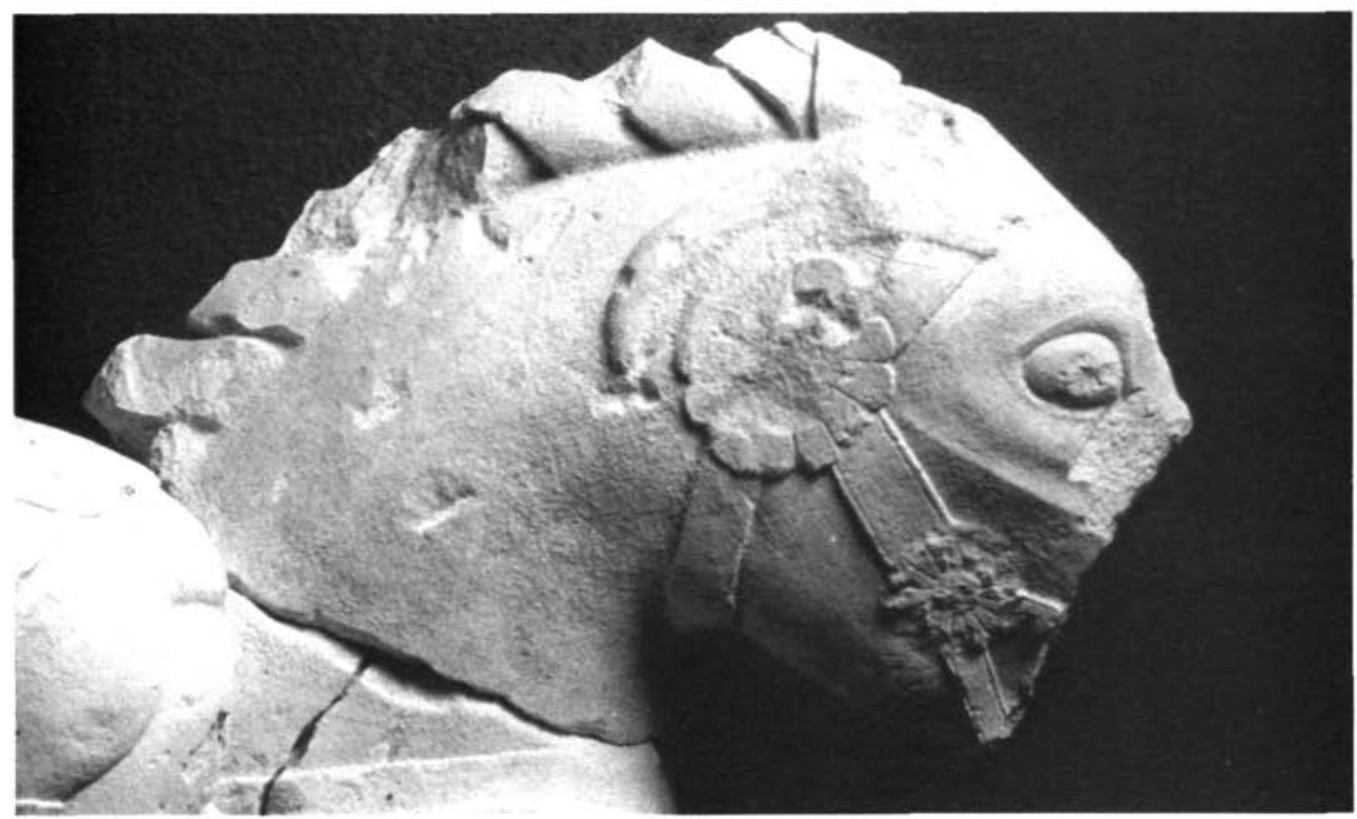

LAM.14- Cabeza de caballo del Cerrillo Blanco de Porcuna (Jaén). 


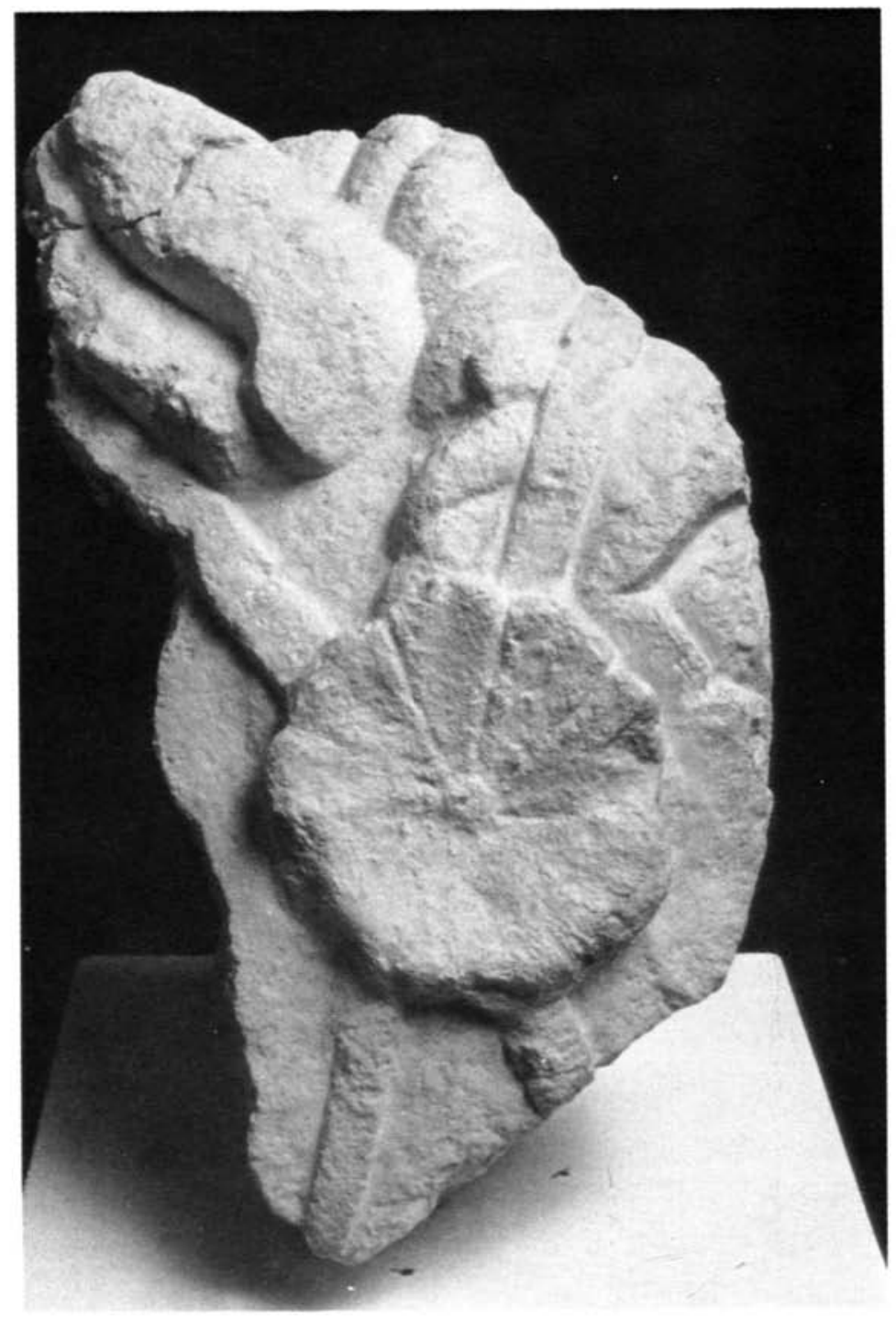

LAM.15- Cabeza de caballo de Casa Quemada (Albacete). 


\section{BIBLIOGRAFIA}

Almagro-Gorbea, M., 1978: "Los relieves mitológicos orientalizantes de Pozo Moro", Trabajos de Prehistoria 35, 251-278.

... 1983a: "Pozo Moro. Un monumento Orientalizante, su contexto socio-cultural y sus paralelos en la arquitectura funeraria ibérica". Madrider Mitteilungen 24, 177-293.

... 1983b: "Pilares-Estela ibéricos". Homenaje al profesor Martín Almagro Basch. vol. III, 7-20, Madrid.

... 1983c: "Colonizzacione e aculturazione nella Penisola Iberica". Modes de Contactset Procesus de transformation dans les Societés Anciennes, École Francaise de Rome, 429-461.

... 1983d: "Los leones de Puente de Noy. Un monumento torriforme funerario en la Península Ibérica". Almuñecar, Arqueologia e Historia, 89-106, Granada.

... 1984: "La colonización focense en la Península Ibérica. Estado actual de la cuestión". I Focei dall'Anatolia all'Aceano, La Parola del Passato 204-207, 432-444.

... 1986: "La iberización de las zonas orientales de la Meseta". Ampurias 38-40, 93-156.

Almagro-Gorbea, M.; Olmos Romera, R., 1983: "Observations sur l'Assimilation de l'Iconographie Classique d'Époque Préromaine dans la Péninsule Ibérique". Mythologie Gréco-Romaine. Mythologies Périphériques. Études d'iconographie, 57-62, Paris.

Bendala Galan, M., 1987: "La Cultura Ibérica", Historia General de España y América, I-2, 223-250, Madrid.

Bendala Galan, M.; Blanquez Perez, J., 1985: "Los orígenes de la cultura ibérica y un par de notas sobre su arte". Iberos, Iojornadas sobre el Mundo Ibérico, 9-18, Jaén.

Blanco Freijeiro, A., 1956: "Orientalia. Estudio de objetos fenicios y orientalizantes en la Península". Archivo Español de Arqueologia XXIX, 3-51.

... 1988: "Las esculturas de Porcuna. III. Animalia". Boletín de la Real Academia de la Historia, tomo CLXXXV, cuaderno II, 205-234.

... 1986-87: "Destrucciones antiguas en el Mundo Ibérico y Mediterráneo Occidental". Homenaje al prof. Gratiniano Nieto. Cuadernos de Prehistoria y Arqueología de la Universidad Autónoma de Madrid 1314, vol. II, 3-8.

Blanquez Perez, J., 1988: "Los enterramientos de estructura tumular en el mundo ibérico". Congreso Peninsular de Historia Antigua, Santiago de Compostela, vol. II, 5-38.

... 1984: "Las necrópolis ibéricas de la provincia de Albacete". Congreso de Historia de Albacete, vol. I, Arqueologia y Prehistoria, 185-209, Albacete.

... 1986-87: "Notas acerca de una revisión de la necrópolis ibérica de la Hoya de Santa Ana (Chinchilla, Albacete)". Cuadernos de Prehistoria y Arqueologia 13-14, Homenaje al Prof. Gratiniano Nieto vol. II, 9-27.

... 1990a. : La formación del mundo ibérico en el Sureste de la Meseta (Estudio arqueológico de las necrópolis ibéricas en la provincia de Albacete). Instituto de Estudios Albacetenses, Serie I, Ensayos Históricos y Científicos $n^{\circ}$. 53, Albacete.

... 1990b, : "La via Heraklea y el Camino de Anibal. Nuevas interpretaciones de su trazado en las tierras del interior". Simposio, La red viaria en la Hispania Romana, 65-76, Zaragoza.

... 1990c: "El factor griego en la formación de las culturas prerromanas de la submeseta sur". Cuadernos de Prehistoria y Arqueología de la Universidad Autónoma de Madrid 17, 9-24.

... 1991a, : "Los iberos". Albacete en su Historia, 27-51, Albacete.

... 1991b: "El impacto del mundo griego en los pueblos ibéricos de la Meseta". Symposium Internacional de Griegos e Ibéricos: siglos VI al IV a. C. Ampurias, Huelva Arqueológica (en prensa).

... 1991c: "En torno al problema de la escultura ibérica". Antonio Blanco Freijeiro. In Memoriam. Manuel Mourelle de Lema Ed., 21-33, Madrid. 
... 1992a. : "Primeras aportaciones arqueológicas sobre la cronología de la escultura ibérica". Homenaje Internacional al prof. José Ma Blázquez Martínez. Universidad Complutense, Madrid, vol. II (en pren$\mathrm{sa})$.

... 1992b, : "Las necrópolis ibéricas en el sureste de la Meseta". Congreso Nacional de Arqueologia ibérica: Las Necrópolis. Serie VARIA 1, 235-278, Madrid.

... 1993a: "El mundo funerario en la fachada oriental de la Península Ibérica y Andalucía. Los componentes indígena y foráneo". Encuentro Internacional. Arqueologia de la Magna Grecia, Sicilia y Peninsula Ibérica. Una aproximación a las relaciones culturales en el marco del Mediterráneo Occidental Clásico. Cordoba 1993 (en prensa)

... 1993b: "Caballeros y aristocracia en el s. V a. C. " Iconografia ibérica e iconografia itálica: propuestas de interpretación y lectura. Roma (en prensa).

Blanquez Perez, J.; Antona del Val, V., 1992: Congreso Nacional de Arqueología ibérica: Las Necrópolis. Serie VARIA 1, Madrid.

Blazquez Martinez, J. M., 1983: "Cinturones sagrados en la Península ibérica". Homenaje al profesor Martin Almagro Basch. vol. II, 411-420.

... 1988: "The Funerary Monument of Jumilla (Murcia, Spain)". American Journal of Archaeology 92, 503-508.

Blazquez Martinez, J. M.; Gonzalez Navarrete, J., 1985: "The Phokaian Sculpture of Obulco in Southern Spain". American Journal Archaeology 89, 61-69.

BLECH, M., 1987: Anotaciones al libro La escultura humana de piedra en el mundo ibérico, por Ruano Ruiz, E., páginas I-XXXVI, Madrid.

Blech, M.;RuAnO, E., 1992: "Zwei Iberische Skulpturen aus Ubeda la Vieja". Madrider Mitteilungen 33, 70-101.

Broncano Rodriguez, S., 1989: El depósito votivo ibérico de El Amarejo. Bonete (Albacete). Excavaciones Arqueológicas en España 156, Madrid.

Castelo Ruano, R., 1990: De arquitectura ibérica: Los elementos arquitectónicos y escultóricos de El Cigaralejo. Mula, Murcia. Madrid.

Chapa Brunet, T., 1984: "Influencias de la colonisation phocéen sur la sculpture ibérique". I Focei dall'Anatolia all'Oceano, La parola del Passato 204-207, 374-392.

... 1986: Influjos griegos en la escultura zoomorfa ibérica. Iberia Graeca, Serie Arqueológica 2, Madrid.

... 1986: "Escultura Ibérica: una revisión de sus interpretaciones". Trabajos de Prehistoria 43, 43-60.

Dominguez Monedero, A., 1991: La polis y la expansión colonial griega. Siglos VIII-VI, Madrid.

Garcia-Gelabert, M. P., Blazquez Martinez, J. M., 1993: "Destrucción de escultura ibérica: Posibles causas". Homenatge a Miquel Tarradell, Estudis Universitaris Catalans, 403-410, Barcelona.

GiménEZ OrTUÑO, LL., 1988: "Noticia sobre una nueva escultura ibérica: el thoracato ibérico de La Losa (Casas de Juan Núñez, Albacete". Homenaje a Samuel de los Santos, 131-135, Albacete.

Lucas Pel.licer, R.; Ruano Ruiz, E., 1990: "Sobre la Arquitectura ibérica de Cástulo (Jaén): Reconstrucción de una fachada monumental", Archivo Español de Arqueologia 63, 43-64.

LLOBREGAT CONESA, E., 1989a: "La sculpture du Levant Ibérique et ses modeles iconographiques". Grecs et Ibéres au IV siécle avant Jésus-Christ. Commerce et Iconographie, Actes de la Table Ronde à Bordeaux 1986, 359-364, París.

... 1989b: "Vías de formación de los modelos iconográficos de la escultura ibérica del País Valenciano". Homenaje al Dr. Sebastián Garcia Martinez, Valencia, 53-62.

... 1993: "Los diversos factores concurrentes en la configuración del arte y la cultura ibéricos". Lengua y Cultura en la Hispania Prerromana, (Untermann, J.;Villar, F. Eds. ), 159-188, Salamanca. 
MuÑoz Amilibia, A. Ma., 1987: "La escultura funeraria de la necrópolis de Coimbra del Barranco Ancho (Jumilla, Murcia). Archivo de Prehistoria Levantina XVII, Homenaje a d. Domingo Fletcher Valls. Tomo I, 229-255.

Negueruela, I., 1990: Los monumentos escultóricos ibéricos del Cerrillo Blanco de Porcuna, Madrid.

NiCOLINI, G., 1969: Les bronzes figurés des santuaires ibériques, París.

Olmos Romera, R., 1986: Anotaciones preliminares al libro de Chapa Brunet, T. : Influjos griegos en la escultura zoomorfa ibérica. Iberia Graeca, Serie Arqueológica 2-38, Madrid.

Olmos, R. et Alii, 1992: La sociedad ibérica a través de la imagen, Madrid.

Perea, A., 1991: Orfebreria Prerromana, Madrid.

Prados Torreira, L., 1992: Exvotos Ibéricos de bronce del Museo Arqueológico Nacional, Madrid.

Ramos Fernandez, R.;Ramos Molina, A., 1992: El monumento y el temenos ibéricos del Parque de Elche, Elche.

Roldan GomeZ, L., 1993a: "Choes y Anthesteria. Nuevos ejemplares en la Península Ibérica". Anuario del Departamento. de Historia y Teoría del Arte V, 1993 (en prensa).

... 1993b: "Cerámicas griegas en el interior peninsular. Nuevas aportaciones". Al-Basit (en prensa).

RUANO RUIZ, E., 1987: La escultura humana de piedra en el mundo ibérico. 3 vols., Madrid.

SANTOS VelasCO, J. A., 1989: "Análisis sobre la transición a una sociedad estatal en la cuenca media del Segura en época ibérica (s. VI-III a. de c. )". Trabajos de Prehistoria 46.

Trillmich, W., 1990: "Early Iberian Sculpture and Phocean Colonization". Greek Colonises and native Populations, procedings of the First Australian Congress of Clasical Archaeology held in honour of Emeritus Professor A. D. Trendall, 607-611, Camberra 1990. 